\title{
Mechanochemical Ring-Opening Metathesis Polymerization: Development, Scope, and Mechano-Only Copolymer Synthesis
}

Gue Seon Lee, ${ }^{\mathrm{a}}$ Hyo Won Lee, ${ }^{\mathrm{a}}$ Hyun Sub Lee, ${ }^{\mathrm{a}}$ Taeyang Do, ${ }^{\mathrm{a}}$ Jean-Louis Do, ${ }^{\mathrm{b}}$ Jeewoo Lim, ${ }^{\mathrm{c}}$ Tomislav Friščić, ${ }^{b^{*}}$ and Jeung Gon Kim ${ }^{\mathrm{a}^{*}}$

a) Department of Chemistry and Research Institute of Physics and Chemistry Jeonbuk National University, Jeonju, 54896, Republic of Korea

E-mail: jeunggonkim@jbnu.ac.kr (J. G. Kim)

b) Department of Chemistry

McGill University, 801 Sherbrooke Street West H3A0B8 Montreal, Canada

E-mail: tomislav.friscic@mcgill.ca (T. Friščić)

c) Department of Chemistry and Research Institute for Basic Science

Kyung Hee University, Seoul 02447, Republic of Korea

\begin{abstract}
Ruthenium-alkylidene initiated ring-opening metathesis polymerization (Ru-ROMP) was realized under solid-state conditions employing a mechanochemical ball milling method, promoting greenness and broadening scope. High-speed ball milling provided sufficient mixing and energy to the reaction mixture comprised of the catalyst and solid monomers, thus eliminating the need for solvents. Studies on the catalytic species and ball milling parameters (liquid-assisted grinding, vibration frequency, and ball size) revealed that mechanical energy regulated solid-state Ru-ROMP and it follows similar mechanistic features of solution-phase reactions. The solubility and miscibility of monomer and Ru-initiator are not a limitation in solid-state ball milling. Without the use of a solvent, a wide spectrum of solid monomers, including ionomer, fluorous monomer, and macromonomers, were successfully polymerized. Finally, effective direct copolymerization of immiscible monomers such ionic/hydrophobic and ionic/fluorous monomers resulted
\end{abstract}


in a set of copolymers that are difficult to make using traditional solution procedures.

\section{Introduction}

Mechanochemical synthesis is a chemical transformation induced by mechanical forces. ${ }^{[1]}$ Efficient mixing and energy delivery using mechanical methods, such as ball milling, have many merits such as solvent-free green synthesis conditions, enhanced reactivity, and unexpected selectivity that conventional methods do not have ${ }^{[2]}$ Over the years, mechanochemical syntheses have been successfully established in many areas along with a better understanding of mechanical actions. ${ }^{[3]}$

For a long time, mechanochemistry has been considered by polymer chemists to be the study of the events related to chain scission or degradation. ${ }^{[4]}$ Breakage and rearrangement of polymer chains induced by mechanical forces have been utilized in many applications. Mechanochemical polymer synthesis beginning with monomers also has a long history. A number of studies on solvent-free mechanochemical polymerization have been sporadically reported since the first report of ball milling free radical polymerization by Kargin in 1959 as efforts toward green and more efficient synthesis, ${ }^{[5]}$ but the important studies by Oprea in the $1970 \mathrm{~s}^{[6]}$ and Kuzuya ${ }^{[7]}$ in the 1990s have not received the attention they deserve. Green chemistry has become a significant topic and mechanochemical polymer synthesis has recently received an increasing amount of research attention. ${ }^{[8]}$ In 2014, Swager demonstrated that the solid-state Gilch polymerization of 2-methoxy-5-2'-ethylhexyloxy phenylene vinylene was achieved after just 5 min of ball milling. ${ }^{[9]}$ Highly efficient and reproducible polymer formation was achieved without the use of liquid-phase reagents. The Borchardt group reported the synthesis of polymers with low solubility, such as poly(phenylene) and poly(azomethine) with a high degree of polymerization. ${ }^{[10]}$ Song and co-workers have demonstrated the high efficiency and promising practicality of ball milling polymerization toward the synthesis of bio-based polyurethane. ${ }^{[11]}$ In addition to the aforementioned stepwise polymerization reactions, chain polymerizations have also been realized under ball milling conditions, aiming at controlled 
polymerization and the production of high-molecular weight products. Adding to early examples of free radical polymerizations by Kargin, Oprea, and Kuzuya (Scheme 1A) ${ }^{[5-7]}$ Kim group reported the solid-state organocatalytic ring-opening polymerization of lactide and trimethylene carbonate under solvent-free ball milling conditions (Scheme 1B). ${ }^{[12]}$ Chain-growth polymerizations involving three components (monomer, initiator, and catalyst) were achieved with high efficiency without the need of a solvent. Undesired chain degradation was controlled using liquid-assisted grinding, allowing a high degree of polymerization and control over the molecular weight of the polymer products. ${ }^{[12 a, b]}$ Recently, the controlled polymerization of a solid vinyl monomer has been reported, which can substantially expand the scope of mechanochemical polymerization. ${ }^{[13]}$ Bielawski and Cho have presented the solid-state atom transfer radical polymerization of 2-vinyl naphthalene and its copolymerization with a conventionally incompatible ionomer, sodium styrene sulfonate. Chemical modification of solid polymers is possible without the need for a solvent. Several examples by Kim, Friščić, Moores, and Hobbs have proven that ball milling can efficiently promote the chemical transformation of polymeric materials and small molecules, sometimes better than their corresponding solution-phase reactions. ${ }^{[14]}$ However, research on mechanochemical polymer synthesis is still in its infancy when compared to that on solution-phase polymerization. The scope of the reported examples is limited. The feasibility of many common polymerization techniques under mechanochemical conditions is obscure. Thus, the synthesis of polymers only obtainable by mechanochemical means remained unexplored.

Many examples of mechanochemical methods have been proven to provide excellent mixing and energy delivery to solid-state materials, which are comparable to their homogeneous liquid-state reactions. Sometimes, the complete dispersion of precursors that would be very difficult to achieve in the liquid state is possible by mechanochemical methods. ${ }^{[15]}$ From this point of view, we envisaged that the solid-state mechanochemistry of widely applicable polymerization techniques, such as ring-opening metathesis polymerization (ROMP), will not only promote green chemistry, but also allow to polymerize previously inaccessible monomers or their combinations to form new materials. Herein, we report the development 
and scope, including copolymerizations previously inaccessible monomer set of ball milling-mediated ROMP in this article (Scheme 1C).

Prior Arts

A) Mechanochemical Radical Polymerization

$\mathrm{n}$<smiles>[R]C=C</smiles><smiles>CC(C)CC(C)C(C)C(C)C</smiles>

- Solid-state free radical polymerizations Kargin (1959), Oprea (1978), Kuzuya (1991)

- Atom transfer radical polymerization Bielawski (2020)

B) Mechanochemical Ring-opening Polymerization<smiles>CC1OC(=O)C(C)OC1=O</smiles>

\section{This Work}

C) Mechanochemical Ring-opening Metathesis Polymerization

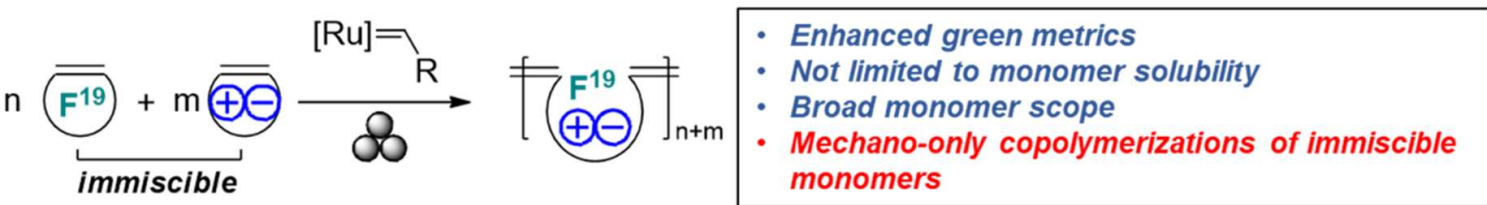

Scheme 1. Solid-state mechanochemical chain polymerizations: A) radical, b) ring-opening, and C) ringopening metathesis polymerizations.

ROMP has deeply impacted many areas of polymer chemistry. ${ }^{[16]}$ Highly active, easy to conduct, and functional group-tolerant Ru-ROMP has dramatically expanded its boundaries. A tremendous amount of effort to improve the efficiency, selectivity, and applicability of this process has been exerted; the development of a sustainable ROMP process has also attracted significant attention to maximize its economic impact and greenness. ${ }^{[17]}$ Given that the solvent takes the largest volume in chemical synthesis, its impact in terms of green chemistry is the first factor to consider. ${ }^{[18]}$ Less-toxic solvents or solvent-free conditions in olefin metathesis have been eagerly pursued. ${ }^{[19]}$ However, only a few studies on solvent-free metathesis polymerization reactions have been reported to date. The Lalabi and Taoufik group has 
demonstrated the ROMP of norbornene over solid-supported tungsten-oxo catalysts. ${ }^{[2]}$ The reaction was conducted in molten norbornene. However, a large amount of norbornene was left. Solvent-free Ru-ROMP has been evaluated by the Hobbs group. ${ }^{[21]}$ High reactivity was observed under highly concentrated conditions, but all of the examples required a homogeneous liquid state to ensure high turnover. Meier and co-workers have demonstrated a highly efficient solvent-free acyclic diene metathesis (ADMET) polymerization reaction using a ruthenium carbene catalyst. ${ }^{[22]}$ However, these systems did not include solid monomers and control over the polymerization reaction is easily lost when the mixture becomes highly viscous or solidifies. In addition, the ROMP of poorly soluble monomers has not been studied. For example, (co)polymerization of ionic monomers lacks common solvents with conventional initiator and monomers, where excellent and unique miscibility by mechanical ball-milling could provide a solution. The modification of metathesis catalysts would be avoided by direct mixing with immiscible monomers.

\section{Results and Discussion}

Rh-Initiator Screening: Ball-Milling vs Solution. Mechanochemical ruthenium-catalyzed olefin metathesis has been previously investigated by Friščić and co-workers using ring-closing and crossmetathesis reactions. ${ }^{[23]}$ Solid-state metathesis is feasible without losing the reactivity. To test its applicability in polymerization, a series of representative ruthenium-alkylidene initiators were chosen to conduct ROMP including Ru-phosphine (G1) and highly reactive Ru-N-heterocyclic carbene (NHC) complexes (G2, G3, and HG2) (Scheme 2). Each initiator (1 mol\%) polymerized the model norbornene monomer (1a) under solvent-free ball-milling conditions (Table 1). All reactions were quenched using a few drops of ethyl vinyl ether after a given vibration time. 
Table 1. Scope of the initiator used in ball-milling ROMP. ${ }^{\text {[a] }}$

\begin{tabular}{|c|c|c|c|c|c|c|}
\hline Entry & {$[\mathrm{Ru}]$} & $\begin{array}{c}\text { Conv }^{[b]} \\
(\%)\end{array}$ & $\begin{array}{c}M_{\mathrm{n}}^{[\mathrm{c}]} \\
(\mathrm{kg} / \mathrm{mol})\end{array}$ & $\begin{array}{c}M_{\mathrm{w}}^{[\mathrm{c}]} \\
(\mathrm{kg} / \mathrm{mol})\end{array}$ & $Ð$ & $E / Z^{[\mathrm{b}]}$ \\
\hline 1 & G1 & 29 & 6.4 & 8.2 & 1.29 & $76 / 24$ \\
\hline 2 & $\mathrm{G} 2$ & 92 & 14.1 & 23.7 & 1.69 & $57 / 43$ \\
\hline 3 & G3 & 97 & 14.5 & 22.2 & 1.53 & $57 / 43$ \\
\hline 4 & HG & 98 & 21.3 & 45.1 & 2.12 & $57 / 43$ \\
\hline 5 & G3(THF) & 99 & 17.2 & 19.7 & 1.14 & $51 / 49$ \\
\hline
\end{tabular}

[a] Reaction condition: 1a $(50 \mathrm{mg})$ and $[\mathrm{Ru}]=1 \mathrm{~mol} \%$ in a $10 \mathrm{~mL}$ zirconia jar containing three zirconia balls $(8 \mathrm{~mm}$ diameter), followed by $30 \mathrm{~Hz}$ vibration for $30 \mathrm{~min} .{ }^{[b]}$ Determined using ${ }^{1} \mathrm{H}$ NMR spectroscopy. ${ }^{[\mathrm{c}]}$ Determined using size exclusion chromatography (SEC) with polystyrene (PS) standards in tetrahydrofuran (THF) at $40{ }^{\circ} \mathrm{C}$.

The general reactivity trends observed in the solution-phase polymerization reaction were maintained in the solid-state ball-milling ROMP. ${ }^{[24]}$ Phosphine-based catalyst G1 exhibited the slowest rate (29\%) after 30 min (entry 1). G1 was inactive in the cross-metathesis reaction in Friščić's experiments, which is not the case for ROMP. ${ }^{[23]}$ Highly reactive Ru-NHC species exhibit $>90 \%$ conversion as expected (entries 2-4). Among the Ru-NHC carbene catalysts studied, G3 with loosely coordinated and, thus, fastinitiating pyridine ligands showed the narrowest dispersity ( $(=1.53$, entry 2$)$. G2 (entry 3 ) and HG2 (entry 4) bearing strong ligands result in broader molecular weight distributions, which are similar to those observed in solution-phase ROMPs. However, the dispersity of $\mathbf{G 3}$ in the solid-state was still much larger than that observed in its solution-phase reaction $(\nexists=1.14$, entry 5$)$. To obtain a narrow dispersity, the 
initiation rate should be higher than the propagation rate. The initiation step in ball milling involves simultaneous physical mixing, which causes a delay in the reaction of the Ru-alkylidene and the first monomer. Thus, the difference between the initiation and propagation rates can be reduced or even reversed, leading to broad dispersity. This hypothesis was supported by entry 1 . The use of the slow-propagating G1 catalyst can alleviate the effect of slow and uneven initiation effects, resulting in a narrower dispersity $(\nexists$ $=1.29$, entry 1). A similar trend in the molecular weight distribution has been previously observed in the solid-state polymerization of trimethylene carbonate using organocatalysts such as 1,8diazabicyclo[5.4.0]undec-7-ene (DBU) and 1,5,7-triazabicyclo[4.4.0]dec-5-ene. (TBD) ${ }^{[12 c]}$ The faster propagation TBD catalyst exhibits broader dispersity than the slower catalyst DBU in the ball-milling chain polymerization reaction because of the inherently retarded initiation step.

The trans and cis ratios of the product polymers were comparable to those observed in their corresponding solution-phase polymerization reactions. ${ }^{[25]} \mathrm{Ru}$-phosphine $\mathbf{G 1}$ preferably produces the $(E)$ isomer (entry 1), and the Ru-NHC catalysts (G2, G3, HG2) exhibited near-equivalent $E / Z$ selectivity (entries $2-4, E / Z=57 / 43$ ). The collective results support the fact that the solid-state Ru-ROMP proceeds via a mechanism similar to that observed in the solution-phase reaction. The temperature variation in each reaction was monitored to determine the reaction phase. The ball-milling equipment was placed in an isotherm container at $30{ }^{\circ} \mathrm{C}$, which was the initial reaction temperature. At the end of the reaction, the temperature of the reaction mixture was measured using an IR thermometer $\left(45-50{ }^{\circ} \mathrm{C}\right)$; this temperature was much lower than the melting point of monomer $1 \mathbf{a}\left(104{ }^{\circ} \mathrm{C}\right)$ and the glass transition of its resulting polymer $\left(141^{\circ} \mathrm{C}\right)$. The reaction mixtures at low, medium, and high conversions did not exhibit any eutectic state. These observations indicate that the polymerization proceeds in the solid state. 
Liquid-Assisted Grinding(LAG): Retarding Mechanically Induced Chain-Degradation. The polymerization reaction was monitored with the ball-milling time (Figure 1). The conversion and numberaverage molecular weight $\left(M_{\mathrm{n}}\right)$ were plotted versus the reaction time for two different initiator-to-monomer ratios $([\mathbf{M}] /[\mathbf{G 3}]=100$ and 200$)$. The conversion reached $>90 \%$ completion after 30 min under both polymerization reactions. However, the molecular weight growth did not follow the monomer conversion. In the case of the $[\mathbf{M}] /[\mathbf{G 3}]=100$ reaction, the highest $M_{\mathrm{n}}(16.7 \mathrm{~kg} / \mathrm{mol})$ was obtained at $30 \mathrm{~min}(90 \%)$; further increasing the ball-milling time gave a diminished molecular weight (60 $\mathrm{min}, 96 \%, 14.2 \mathrm{~kg} / \mathrm{mol}$ ). When using 200 equiv. of monomer with respect to G3, the final product did not exhibit a two-fold increase in the $M_{\mathrm{n}}$ when compared to the product obtained using 100 equiv.; however, the product was formed with a similar $M_{\mathrm{n}}(16.2 \mathrm{~kg} / \mathrm{mol})$. Reaction monitoring revealed that the maximum $M_{\mathrm{n}}(24.3 \mathrm{~kg} / \mathrm{mol})$ was reached at an early stage of the polymerization (10 $\mathrm{min}, 50 \%$ conversion, $24.3 \mathrm{~g} / \mathrm{mol})$. Gradual degradation was observed upon further reaction of the monomer. These results imply that chain propagation and degradation occur at the same time. The chain degradation process was considerable after $M_{\mathrm{n}} \sim 15 \mathrm{~kg} / \mathrm{mol}$. Similar observations have been repeatedly reported in the ball-milling synthesis of poly(phenylene vinylene), poly(lactic acid), poly(trimethylene carbonate), polyphenylene, and poly(2-vinyl naphthalene). ${ }^{[7 a, 9,10,12,13]}$ Another possibility is that the decreased molecular weight originates from the chain backbiting reaction of the reactive Ru-chain end. ${ }^{[26]}$ However, the backbiting process is usually dominant when the monomer concentration is low. In this case, the decrease in the molecular weight begins at a low monomer conversion. Thus, mechanical action was proposed to be the dominant cause of the chain scission process. 

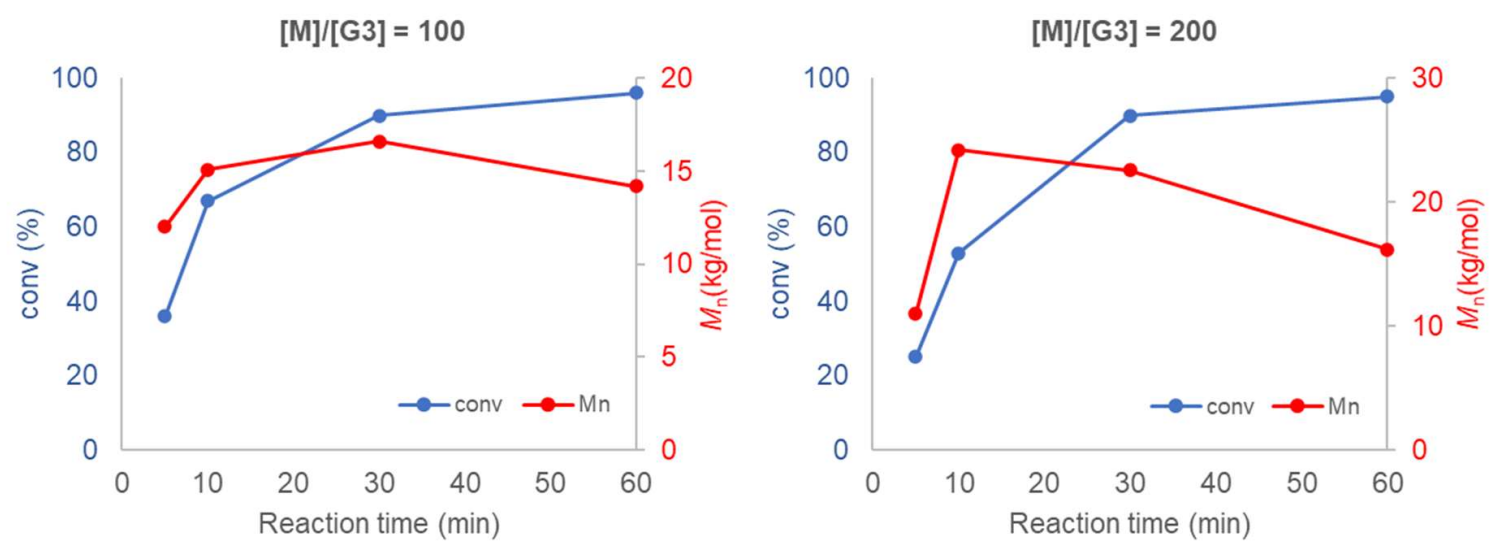

Figure 1. Conversion and number average molecular weight vs. ball-milling time.

Liquid-assisted grinding (LAG) was examined to alleviate the chain degradation process (Table 2). ${ }^{[27]}$ Previously, we observed that the addition of a very small portion of liquid could reduce the chain degradation process. ${ }^{[12 a, b]}$ The uniform distribution of small molecules in the polymer matrix was expected to lubricate the polymer chains or dissipate the impact energy. Therefore, $20 \mu \mathrm{L}$ of the selected liquid $(\eta=$ $\left.0.4 \mu \mathrm{Lmg}^{-1}\right)$ was added to the mixture consisting of monomer $1 \mathbf{a}(50 \mathrm{mg})$ and $\mathrm{G} 3(0.5 \mathrm{~mol} \%)$. We chose a group of solvents conventionally used in Ru-ROMP for our LAG experiments (entries 2-4) and compared them with their corresponding neat grinding (entry 1) and solution-phase reactions (entries 5 and 6 ). Toluene did not effectively improve the $M_{\mathrm{n}}$ (entry 2). THF resulted in a marginal increase of $2.9 \mathrm{~kg} / \mathrm{mol}$ in the $M_{\mathrm{n}}$ and an improvement of $6.9 \mathrm{~kg} / \mathrm{mol}$ in the $M_{\mathrm{w}}$ (entry 3). Interestingly, 1,2-dichloroethane (DCE) exhibits a substantial effect (entry 4) with an $\sim 10 \mathrm{~kg} / \mathrm{mol}$ increase in the $M_{\mathrm{n}}$ and a significant narrowing of the dispersity. To gain more details on the LAG effect, we compared the shape of the gel permeation chromatograms obtained for selected polymer products (Figure 2). The addition of toluene gives similar $M_{\mathrm{n}}$ and $M_{\mathrm{w}}$ to the neat grinding reaction (entry 1, blue line in Figure 2). However, the peak molecular weight $\left(M_{\mathrm{p}}\right)$ of the toluene added polymerization product $(46.6 \mathrm{~kg} / \mathrm{mol}$, red line in Figure 2) was $12.9 \mathrm{~kg} / \mathrm{mol}$ higher than that obtained using neat grinding $(33.7 \mathrm{~kg} / \mathrm{mol})$ and nearly identical to the $M_{\mathrm{p}}$ of the solution-phase reaction $(48.0 \mathrm{~kg} / \mathrm{mol}$, green line in Figure 2). LAG with toluene efficiently protects the polymer chains from mechanical forces. The increased small $M_{\mathrm{w}}$ portion, which was probably due to the slow initiation, 
accounts for the low $M_{\mathrm{n}}$. In the case of THF (entry 3 ), the $M_{\mathrm{p}}$ shifts to a higher value when compared to the solution-phase reactions. Chain protection and fast initiation were simultaneously achieved when DCE was added (dashed line in Figure 2). LAG helped both material dispersion and chain protection.

Table 2. Effect of liquid-assisted grinding. ${ }^{[a]}$

\begin{tabular}{|c|c|c|c|c|c|c|}
\hline Entry & Liquid & $\begin{array}{c}\text { Conv }^{[b]} \\
(\%)\end{array}$ & $\begin{array}{c}M_{\mathrm{n}}^{[\mathrm{c}]} \\
(\mathrm{kg} / \mathrm{mol})\end{array}$ & $\begin{array}{c}M_{\mathrm{w}}^{[\mathrm{c}]} \\
(\mathrm{kg} / \mathrm{mol})\end{array}$ & $\begin{array}{c}M_{\mathrm{p}}^{[\mathrm{c}]} \\
(\mathrm{kg} / \mathrm{mol})\end{array}$ & $Ð$ \\
\hline 1 & None & 89 & 22.6 & 37.7 & 33.7 & 1.67 \\
\hline 2 & Toluene & 99 & 23.0 & 38.9 & 46.6 & 1.71 \\
\hline 3 & THF & 96 & 25.5 & 44.6 & 55.7 & 1.74 \\
\hline 4 & DCE & 99 & 32.3 & 43.4 & 46.1 & 1.29 \\
\hline $5^{[\mathrm{d}]}$ & $\begin{array}{c}\text { THF } \\
\text { (Solution) }\end{array}$ & 99 & 40.0 & 46.5 & 48.0 & 1.16 \\
\hline $6^{[\mathrm{d}]}$ & $\begin{array}{c}\text { DCE } \\
\text { (Solution) }\end{array}$ & 99 & 40.4 & 48.1 & 51.4 & 1.19 \\
\hline
\end{tabular}

${ }^{[a]}$ Reaction conditions: 1a (50 mg), G3, and liquid $(20 \mu \mathrm{L})$ in a $10 \mathrm{~mL}$ zirconia jar containing three zirconia balls (8 $\mathrm{mm}$ diameter), followed by $30 \mathrm{~Hz}$ vibration for $30 \mathrm{~min} .{ }^{[b]}$ Determined using ${ }^{1} \mathrm{H}$ NMR spectroscopy. ${ }^{[c]}$ Determined using SEC with PS standards in THF at $40{ }^{\circ} \mathrm{C}$. ${ }^{[d]}$ Reactions were performed using $0.4 \mathrm{~mL}$ of solvent $([\mathrm{M}]=0.5 \mathrm{M})$ for $30 \mathrm{~min}$. 


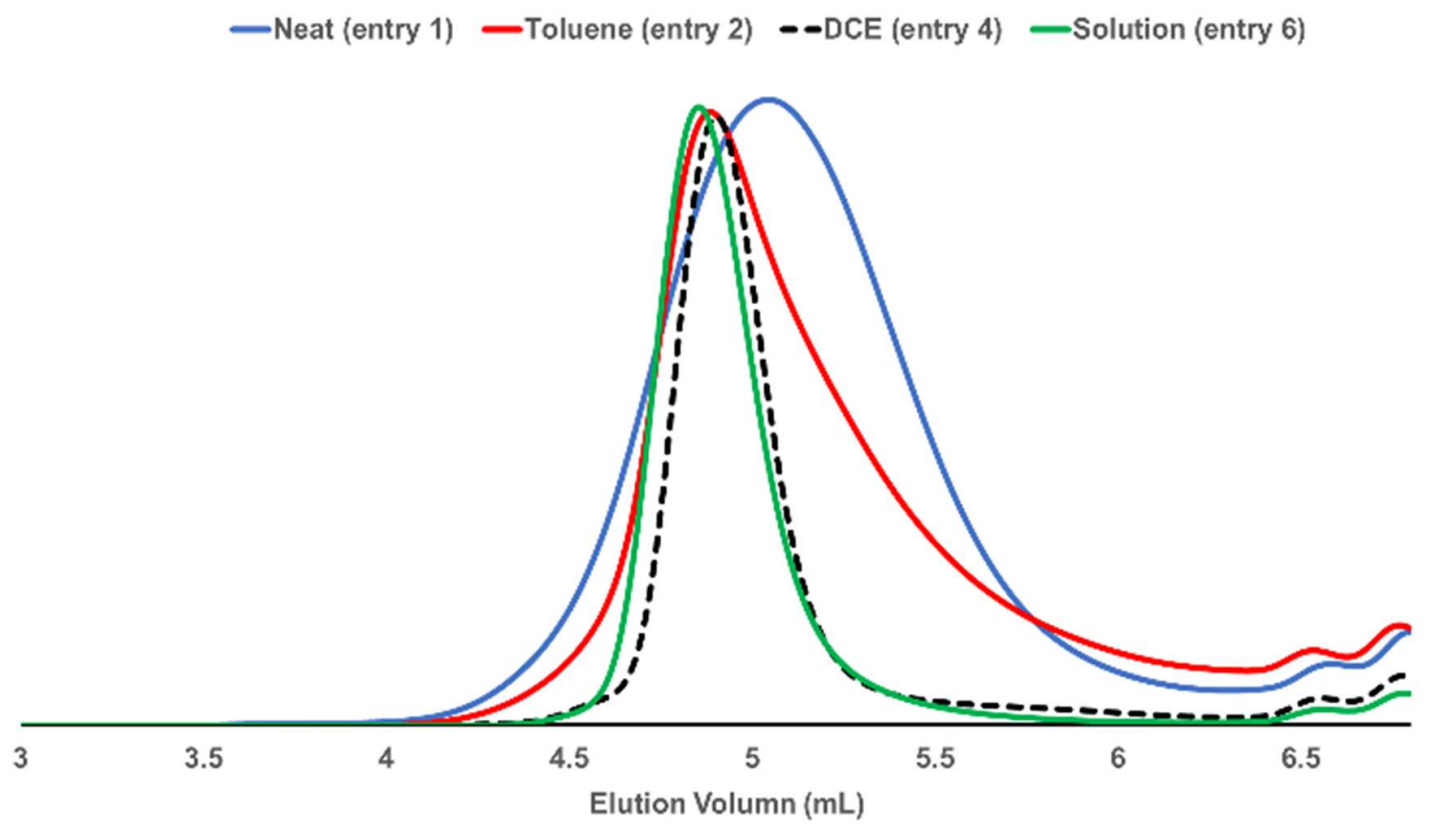

Figure 2. SEC traces obtained for selected polymers from Table 2.

Evaluation of Ball-Milling Parameters. Subsequently, different milling parameters were investigated (Table 3). To evaluate both the polymerization and degradation efficiency, $[\mathbf{M}] /[\mathbf{G} 3]=200$ was used. Changing the number of milling balls was not an important factor (entries 1-3). Ball-milling with one 8 mm ball converted $87 \%$ of monomer 1a to the polymer (entry 1). Three and five $8 \mathrm{~mm}$ balls resulted in 90 and $93 \%$ conversion, respectively (entries 2 and 3). The degradation levels were similar. Similar molecular weights were obtained regardless of the number of milling balls used. However, variations in the ball size had a pronounced effect on the polymerization reaction. Changing to a heavier $10 \mathrm{~mm}$ ball resulted in the full consumption of the monomer, whereas the use of $5 \mathrm{~mm}$ balls $(\times 12)$ only gave a $16 \%$ turnover and 3 mm balls $(\times 20)$ showed almost no conversion. As seen in ring-opening lactide polymerization, ${ }^{[12 a]}$ the importance of the collision energy on the reaction efficiency was again confirmed in ROMP. At the same time, high-energy ball milling affected the degree of chain degradation. The experiment using a $10 \mathrm{~mm}$ ball 
produced a polymer product with a lower number average molecular weight than that obtained using $8 \mathrm{~mm}$ ball conditions ( 24.1 vs. $16.5 \mathrm{~kg} / \mathrm{mol}$ ). The effect of the vibration frequency was evaluated at $20 \mathrm{~Hz}$ (entry 7). Slower vibration provided poor mixing and low-energy delivery, resulting in a low conversion (16\%).

Table 3. Effect of the ball-milling parameters. ${ }^{[\mathrm{a}]}$

$\mathrm{n}$<smiles></smiles>

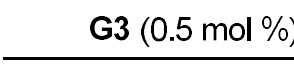

$1 \mathrm{a}$ Varied balls $30 \mathrm{~Hz}, 30 \mathrm{~min}$<smiles>C=CC1CC(C=C)C2C(=O)N(Cc3ccccc3)C(=O)C12</smiles>

\begin{tabular}{cccccc}
\hline Entry & Balls & $\begin{array}{c}\text { Conv }^{[\mathrm{b}]} \\
(\%)\end{array}$ & $\begin{array}{c}M_{\mathrm{n}}^{[\mathrm{c}]} \\
(\mathrm{kg} / \mathrm{mol})\end{array}$ & $\begin{array}{c}M_{\mathrm{w}}^{[\mathrm{cc}} \\
(\mathrm{kg} / \mathrm{mol})\end{array}$ & $Ð$ \\
\hline 1 & $8 \mathrm{~mm} \times 1$ & 87 & 24.1 & 39.5 & 1.64 \\
\hline 2 & $8 \mathrm{~mm} \times 3$ & 90 & 22.6 & 37.7 & 1.67 \\
\hline 3 & $8 \mathrm{~mm} \times 5$ & 93 & 23.0 & 37.8 & 1.65 \\
\hline 4 & $10 \mathrm{~mm} \times 1$ & 98 & 16.5 & 27.2 & 1.65 \\
\hline 5 & $5 \mathrm{~mm} \times 12$ & 16 & N/A & N/A & N/A \\
\hline 6 & $3 \mathrm{~mm} \times 20$ & 1 & N/A & N/A & N/A \\
\hline 7 & $8 \mathrm{~mm} \times 3$ & 16 & N/A & N/A & N/A \\
\hline
\end{tabular}

[a] Reaction conditions: 1a (50 mg) and $\mathbf{G 3}$ in a $10 \mathrm{~mL}$ zirconia jar, followed by $30 \mathrm{~Hz}$ vibration for $30 \mathrm{~min}$. ${ }^{\text {[b] }}$ Determined using ${ }^{1} \mathrm{H}$ NMR spectroscopy. ${ }^{[\mathrm{cc}}$ Determined using SEC with PS standards in THF at $40{ }^{\circ} \mathrm{C}$.

Livingness \& Block Copolymerization. One of the most important features of Ru-ROMP is its livingness. The active chain end after full consumption of the monomer can accept a second monomer, resulting in its corresponding block copolymer. To evaluate livingness, the sequential addition of 1a was investigated. After 10 min of grinding of the first portion of monomer 1a (100 equiv., 91\% conversion) and G3, the second portion of 1a (100 equiv.) was added, and grinding continued. However, a large portion of the first block remained unreacted (Figure 3). Therefore, the formation of block copolymers via the sequential 
addition of the monomer was not viable. As of now, it is not clear what occurs at the ruthenium alkylidene end; further studies, including the termination pathway under solid-state conditions, are ongoing in our laboratory.

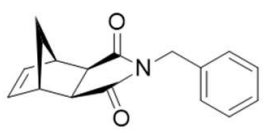

$50 \mathrm{mg}$ (100 equiv.)

$1 a$

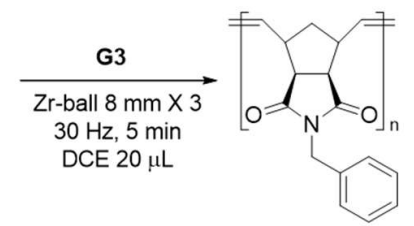

P1 (91\% conv)

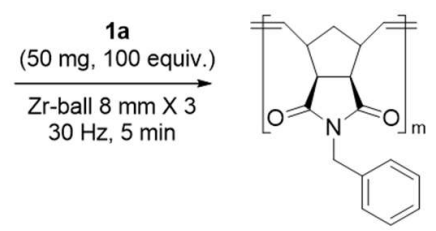

P2 (99\% conv)

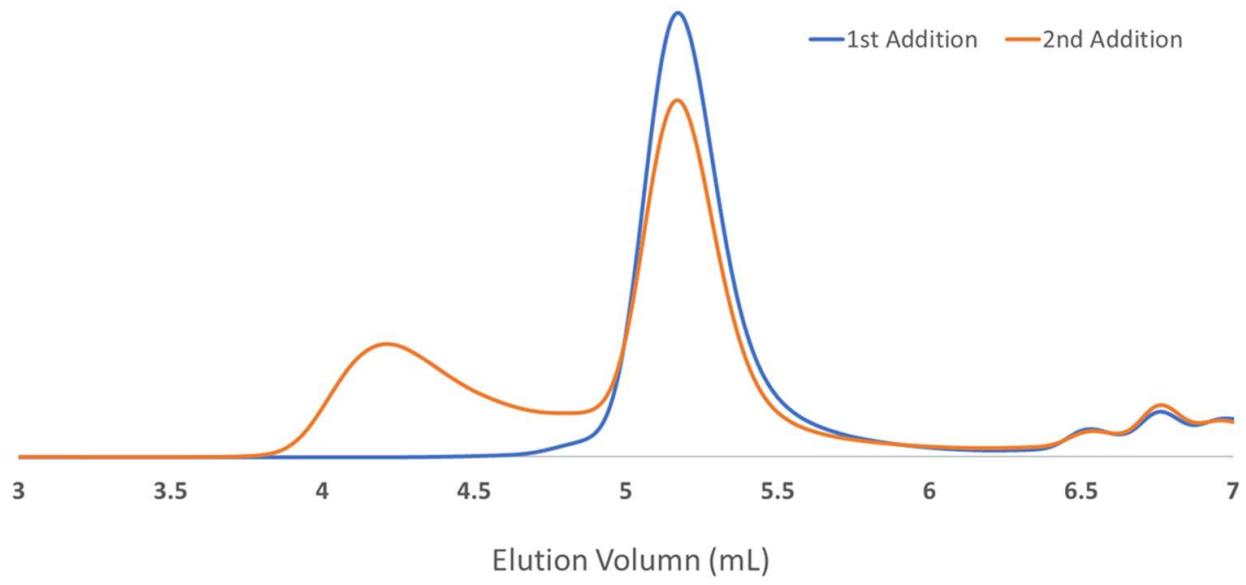

Figure 3. SEC traces obtained of sequential monomer 1a addition experiment.

Scope of Monomers. A variety of solid monomers were used under the optimized ball-milling polymerization conditions (Table 4). 100 to 300 equiv. of monomer 1a were polymerized and a linear increase in the molecular weights was observed (entries 1-3). The LAG of DCE $(\eta=0.4)$ minimized chain degradations: a control of molecular weight was achieved. The high functional group compatibility of the ruthenium metathesis catalyst was also observed in the solid-state ROMP. Initiator G3 maintained its 
metathesis reactivity in the presence of highly concentrated hydroxy (1b), carboxylic acid (1c), and ester (1d) groups (entries 4-6). Exceptional mixing efficiency of high-speed ball milling has great potential in polymerization of monomers with orthogonal solubilities to G3. Several Ru-ROMP examples in aqueous media have been previously reported. ${ }^{[28]}$ However, modification of the Ru catalyst with ionic pendants was required to make the catalyst soluble in water. In the solid-state ball milling ROMP, the unmodified $\mathbf{G 3}$ initiator exhibits excellent efficiency (99\%) in the polymerization of zwitterionic monomer 1e (entry 7). Next, the production of a fluorous polymer was achieved by direct ball milling. The highly fluorineenriched monomer 1 f was commenced to G3 initiator (entry 8). The LAG of a 1:1 mixture of THF and HFE-7100 $\left(\mathrm{C}_{4} \mathrm{~F}_{7} \mathrm{OCH}_{3}\right)(\eta=0.4)$ provided sufficient mixing of $\mathbf{1} \mathbf{f}$ and $\mathbf{G 3}$, and the corresponding fluorouspolymer was obtained quantitatively. Another interesting class of monomers, norbornenyl-terminated macromolecules (NB-MM), can be polymerized (entries 9 and 10), giving bottlebrush polymers. ${ }^{[29]}$ The excellent catalytic efficiency of $\mathbf{G 3}$ in the grafting-through polymerization of NB-MM was sustained under solid-state conditions. Representative norbornene-terminated poly(lactic acid) and poly(ethylene glycol) macromonomers were efficiently polymerized using THF-LAG. 
Table 4. Scope of the monomer in the solid-state ROMP. ${ }^{\text {[a] }}$

\begin{tabular}{|c|c|c|c|c|c|c|}
\hline Entry & Monomer & {$[\mathrm{M}] /[\mathrm{G} 3]$} & LAG & $\begin{array}{c}\mathrm{Conv}_{(\%)}^{[\mathrm{b}]} \\
\end{array}$ & $\begin{array}{c}M_{\mathrm{n}}^{[\mathrm{c}]} \\
(\mathrm{kg} / \mathrm{mol})\end{array}$ & $Ð$ \\
\hline 1 & & 100 & none & 97 & 14.5 & 1.53 \\
\hline 2 & & 200 & $\begin{array}{c}\text { DCE } \\
(\eta=0.4)\end{array}$ & 99 & 32.3 & 1.29 \\
\hline 3 & $1 \mathbf{a}$ & 300 & $\begin{array}{c}\text { DCE } \\
(\eta=0.4)\end{array}$ & 99 & 54.9 & 1.17 \\
\hline 4 & $1 \mathrm{~b}$ & 100 & none & 98 & $69.9^{[\mathrm{d}]}$ & $1.72^{[\mathrm{d}]}$ \\
\hline 5 & 1c & 100 & none & 97 & N/A & N/A \\
\hline 6 & 1d & 100 & none & 91 & 18.2 & 1.53 \\
\hline 7 & $1 e$ & 100 & $\begin{array}{c}\mathrm{H}_{2} \mathrm{O} \\
(\eta=0.4)\end{array}$ & 99 & $24.7^{[\mathrm{e}]}$ & $1.36^{[\mathrm{e}]}$ \\
\hline 8 & 1f & 50 & $\begin{array}{c}\mathrm{THF} / \mathrm{HFE} \\
{[\mathrm{d}](1: 1)} \\
(\eta=0.4)\end{array}$ & 99 & N/A & N/A \\
\hline $9^{[\mathrm{f}]}$ & $\begin{array}{c}\mathrm{NMR})=2.6 \mathrm{~kg} / \\
\mathbf{1 g}\end{array}$ & 100 & $\begin{array}{c}\text { THF } \\
(\eta=0.4)\end{array}$ & 96 & 97.3 & 1.29 \\
\hline $10^{[\mathrm{f}]}$ & $\begin{array}{c}(\mathrm{MR})=1.9 \mathrm{~kg} / \mathrm{m} \\
\mathbf{1 h}\end{array}$ & 50 & $\begin{array}{c}\text { THF } \\
(\eta=0.4)\end{array}$ & 93 & $72.4^{[\mathrm{d}]}$ & 1.25 \\
\hline
\end{tabular}




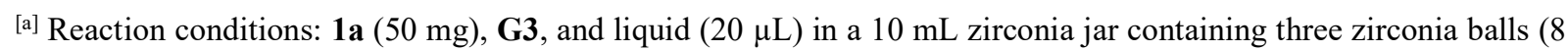
$\mathrm{mm}$ diameter), followed by $30 \mathrm{~Hz}$ vibration for $30 \mathrm{~min} .{ }^{[\mathrm{b}]}$ Determined using ${ }^{1} \mathrm{H}$ NMR spectroscopy. ${ }^{[\mathrm{c}]}$ Determined using SEC with polystyrene standards in tetrahydrofuran at $40{ }^{\circ} \mathrm{C}$. ${ }^{\mathrm{d}]}$ Determined using SEC with polystyrene standards in dimethylformamide at $40{ }^{\circ} \mathrm{C}$. ${ }^{[\mathrm{e}]}$ Determined using SEC with poly(ethylene oxide) standards in $\mathrm{H}_{2} \mathrm{O}$ at $40^{\circ} \mathrm{C} .{ }^{[\mathrm{f}]}$ Milling time $=60 \mathrm{~min}$.

Synthesis of Mechano-only Copolymers. Copolymers comprised of neutral and ionic monomers are found in many applications. ${ }^{[30]}$ However, the orthogonal solubility of these monomers, thus lack of common solvents, has challenged their synthesis. Multi-step polymerization and post-polymerization modifications have been practiced. ${ }^{[31]}$ The compatibility of Ru-initiator with monomers is also a concern in the Ru-ROMP. ${ }^{[28]}$ As previously stated, polymerization in a hydrophilic system necessitated Ru-complex modification, such as the addition of a polar unit to a ligand. However, those initiators are not compatible with hydrophobic monomers and vice versa. Several recent studies have shown that under ball milling settings, immiscibility in solution is not a problem. Solvent-free direct ball milling was used to successfully combine

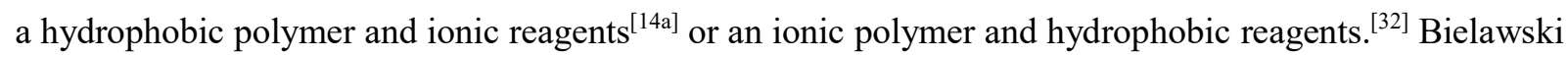
also showcased the ATRP of incompatible monomers in solid-state. ${ }^{[13]}$ Thus, we envisioned that mechanochemical ROMP would copolymerize monomers of orthogonal solubility with one initiator. Table 4 shows that regardless of the polarity of the monomers, including ionic and fluorous monomers, mechanochemical ball-milling with G3 produced high polymerization efficiency. Subsequently, their copolymerizations were investigated. In ball-milling, the hydrophobic monomer $1 \mathbf{a}$ and the ionic monomer 1e were polymerized, resulting in copolymers with varying compositions (Table 5). After each reaction, an aliquot was transferred to trace unreacted monomers. Most of the reactions exhibited good concurrent conversion of both 1a and 1e except entry 4 that the minor component hydrophobic 1a reached $83 \%$ conversion while hydrophilic 1e was consumed completely. The solubility of the resulting copolymers was dictated by the major component. Hydrophobic polymers were produced in entries 2 and 3, and entries 4 and 5 were hydrophilic polymers. Only main components were found using ${ }^{1} \mathrm{H}-\mathrm{NMR}$ spectrometers (figure S3). The coexistence of two repeat units was established by the IR spectra (figure S4). The peak of $\mathrm{S}=\mathrm{O}$ 
$\left(1034 \mathrm{~cm}^{-1}\right)$ in $1 \mathrm{e}$ coexisted with the peaks of C-N $\left(1165 \mathrm{~cm}^{-1}\right)$ and phthalimide $\left(1717 \mathrm{~cm}^{-1}\right)$ in $1 \mathrm{a}$ in all copolymers. The copolymerization of fluorous (1f) and ionic (1i) monomers took place under similar conditions (Scheme 2). ROMP of $\mathbf{1 f}$ and 1i (1:2 ratio) gave the corresponding copolymer. The product's IR spectra revealed both peaks, $\mathbf{1 f}$ ester and 1i phthalimide (figure S5). The relative intensities of the peaks matched those of the monomer mixture, proving successful copolymerization that is hard to obtain in solution conditions. 
Table 5. Copolymerizations of immiscible monomers with G3.

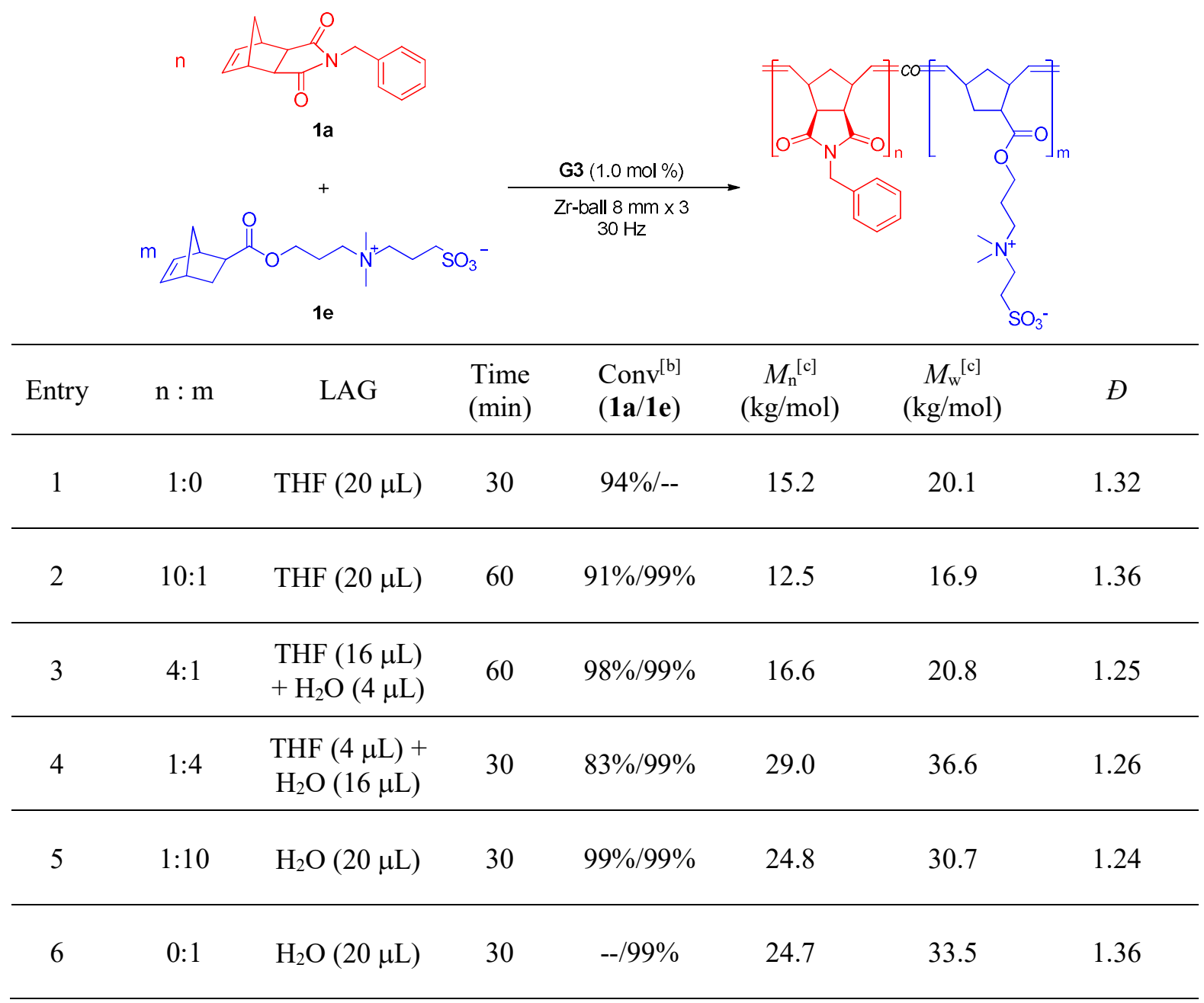

${ }^{[\mathrm{a}]}$ Reaction conditions: 1a $+\mathbf{1 e}(50 \mathrm{mg}), \mathbf{G 3}(1.0 \mathrm{~mol} \%)$, and liquid $(20 \mu \mathrm{L})$ in a $10 \mathrm{~mL}$ zirconia jar containing three zirconia balls (8 mm diameter), followed by $30 \mathrm{~Hz}$ vibration. ${ }^{[b]}$ Determined using ${ }^{1} \mathrm{H}$ NMR spectroscopy. ${ }^{[c]}$ Determined using SEC with polystyrene standards in tetrahydrofuran at $40{ }^{\circ} \mathrm{C}$. ${ }^{\mathrm{d}]}$ Determined using SEC with polystyrene standards in dimethylformamide at $40{ }^{\circ} \mathrm{C}$. ${ }^{[\mathrm{e}]}$ Determined using SEC with poly(ethylene oxide) standards in $\mathrm{H}_{2} \mathrm{O}$ at $40{ }^{\circ} \mathrm{C}$. 


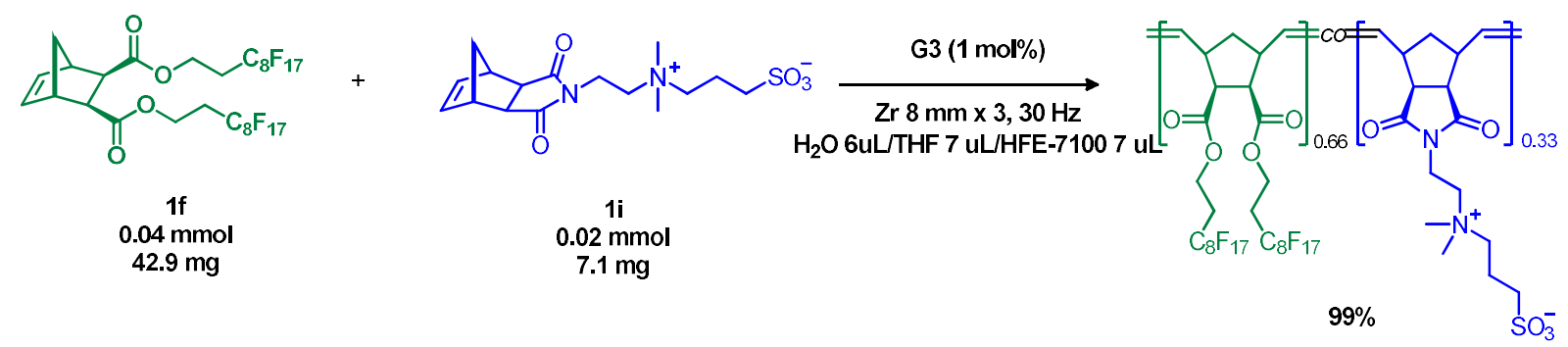

Scheme 2. Copolymerization of immiscible fluorous monomer (1f) and ionomer (1i).

\section{Conclusion}

We have proven that ROMP, one of the most versatile methods used for functional polymer synthesis, is possible under solid-state ball milling conditions. Unmodified Ru-alkylidene G3 maintained its reactivity and versatility without the need for a solvent. High-speed ball milling provides sufficient mixing and energy. The use of liquid additives has a positive effect. LAG is essential for the preparation of polymer products with high molecular weight and narrow dispersity. This mechanochemical system showed a broad monomer scope, including challenging classes such as ionic and fluorous monomers as well as macromonomers. The orthogonal solubilities among monomers and initiators were not a problem anymore in solid-state ball milling conditions. The copolymerization examples of hydrophobic/ionic monomers and fluorous/ionic monomers produced mechano-only polymers, which allowed the expedition to new properties and applications, which will follow by our further research. 


\section{Methods}

\section{General experimental procedure for ball milling-promoted ROMP(Table 2, entry 4).}

All chemical transfers and vessel assembly were conducted in a nitrogen-purged dry-box. Monomer 1a $(0.20 \mathrm{~g})$ and DCE $(40 \mathrm{~mL})$ were added to a zirconia milling container $(10 \mathrm{~mL})$ having $8 \mathrm{~mm}$ zirconia balls (3 ea.). A solution of $\mathbf{G 3}$ in DCE was added to the top closure. This part was left for a minute to allow the DCE to evaporate leaving the designated amount of $\mathbf{G 3}(0.50 \mathrm{~mol} \%)$. The main vessel and top closure were assembled. The vessel was placed in a vibrational ball-milling machine and milled for $30 \mathrm{~min}$ in a thermostat at $30{ }^{\circ} \mathrm{C}$. The milling vial was opened. A few drops of ethyl vinyl ether were added to quench the polymerization, followed by an additional $5 \mathrm{~min}$ of ball milling. A portion of the solid mixture was subjected to ${ }^{1} \mathrm{H}$ NMR spectroscopy and SEC analysis to determine the conversion and molecular weights. The average of the two experiments was reported: 99\% conversion ( $\left.{ }^{1} \mathrm{H} \mathrm{NMR}, \mathrm{CDCl}_{3}\right) ; M_{\mathrm{n}}=32.3 \mathrm{~kg} / \mathrm{mol}$, $Ð=1.29$ (SEC in THF, PS-standard).

\section{Acknowledgments}

This work was supported by the Samsung Science \& Technology Foundation (SRFC-MA1902-05).

\section{Author information}

\section{Contributions}

J.G.K. and T.F. conceived, designed, and originated this project. D.T. conducted the initial experiments. G.S.L, H.W.L, H.S.L, and J.-L.D. performed the experiments, obtained all date and analysed the results. J.G.K and T.F. wrote the manuscript. J.L. provided fluorine monomer and confirmed the data. All authors read and confirmed the manuscript and supporting information. 


\section{Corresponding author}

Correspondence to Jeung Gon Kim and Tomislav Friščić 


\section{References}

[1] a) James, S. L. \& Friščić, T. Mechanochemistry. Chem. Soc. Rev. 42, 7494-7496 (2013).

b) James, S. L. \& Friščić, T. Mechanochemistry: a web themed issue. Chem. Commun. 49, $5349-5350(2013)$.

c) Gilman, J. J. Mechanochemistry. Science 274, 65 (1996).

[2] a) James, S. L. et al. Mechanochemistry: opportunities for new and cleaner synthesis. Chem. Soc. Rev. 41, 413-447 (2012).

b) Hernández, J. G. Mechanochemistry. Beilstein J. Org. Chem. 13, 2372-2373 (2017).

c) J.-L. Do \& J.-L., Friščić, T. Mechanochemistry: A force of synthesis. ACS Cent. Sci. 3, 13-19 (2017).

d) Friščić, T., Mottillo, C. \& Titi, H. M. Mechanochemistry for synthesis. Angew. Chem. Int. Ed. 59, 1018-1029 (2020).

[3] a) Wang, G.-W. Mechanochemical organic synthesis. Chem. Soc. Rev. 42, 7668-7700 (2013). b) Porcheddu, A., Colacino, E., De Luca, L. \& Delogu, F. Metal-mediated and metal-catalyzed reactions under mechanochemical conditions. ACS Catal. 10, 8344-8394 (2020).

c) Stolle, A., Szuppa, T., Leonhardt, S. E. S. \& Ondruschka, B. Ball milling in organic synthesis: solutions and challenges. Chem. Soc. Rev. 40, 2317-2329 (2011).

d) Tan, D. \& Friščić, T. Mechanochemistry for organic chemists: An update. Eur. J. Org. Chem. 2018, 18-33 (2018).

e) Rightmire, N. R. \& Hanusa, T. P. Advances in organometallic synthesis with mechanochemical methods. Dalton Trans. 45, 2352-2362 (2016).

f) Moores, A. Bottom up, solid-phase syntheses of inorganic nanomaterials by mechanochemistry and aging. Curr. Opin. Green Sustain. Chem. 12, 33-37 (2018).

g) Boldyreva, E. Mechanochemistry of inorganic and organic systems: what is similar, what is 
different? Chem. Soc. Rev. 42, 7719-7738 (2013).

h) Tan, D. \& García, F. Main group mechanochemistry: from curiosity to established protocols. Chem. Soc. Rev. 48, 2274-2292 (2019).

[4] a) Li, J., Nagamani, C. \& Moore, J. S. Polymer mechanochemistry: from destructive to productive. Acc. Chem. Res. 48, 2181-2190 (2015).

b) Kean, Z. S. \& Craig, S. L. Mechanochemical remodeling of synthetic polymers. Polymer 53, $1035-1048(2012)$.

c) Chen, Z. et al. Mechanochemical unzipping of insulating polyladderene. Science 357, 475-479 (2017). d) Imato, K. et al. Mechanochromic dynamic covalent elastomers: quantitative stress evaluation and autonomous recovery. ACS Macro Lett. 4, 1307-1311 (2015).

[5] a) Plate, K. A. \& Kargin, V. A. Chemical grafting on crystal surfaces. Vysokomol. Soedin. 1, 330 (1959).

b) Plate, K. A. \& Kargin, V. A. Mechanochemical reactions of polymerization and degradation at low temperatures. J. Polym. Sci., Part C: Polym. Symp. 4, 1027-1041 (1963).

[6] a) Oprea, C. V. \& Popa, M. Mechanochemisch ausgelöste polymerisationsreaktionen I. mechanochemische homopolymerisation durch schwingmahlung von styrol und acrylnitril. Angew. Makromol. Chem. 68, 1-15 (1978).

b) Oprea, C. V. \& Popa, M. Mechanochemically synthesized polymers with special properties. Polym. Plast. Technol. Eng. 28, 1025-1058 (1989).

c) Simionescu, C., Oprea, C. V. \& Nicoleanu, J. Mechanochemically initiated polymerizations5. polymerization by vibratory milling of acrylamide and methacrylamide. Eur. Polym. J. 19, 525$528(1983)$.

[7] a) Kuzuya, M., Kondo, S. \& Noguchi, A. A new development of mechanochemical solid-state polymerization of vinyl monomers: prodrug syntheses and its detailed mechanistic study. 
Macromolecules 24, 4047-4053 (1991).

b) Kuzuya, M., Kondo, S.-I., Noguchi, A. \& Noda, N. Mechanistic study on mechanochemical polymerization of acrylamide. J. Polym. Sci. Part A: Polym. Chem. 29, 489-494 (1991).

[8] a) Anastas, P. T. \& Kirchhoff, M. M. Origins, current status, and future challenges of green chemistry. Acc. Chem. Res. 35, 686-694 (2002).

b) Ardila-Fierro, K. J. \& Hernández, J. G. Sustainability assessment of mechanochemistry by using the twelve principles of green chemistry. ChemSusChem 14, 2145-2162 (2021)

[9] Ravnsbæk, J. B. \& Swager, T. M. Mechanochemical synthesis of poly(phenylene vinylenes). ACS Macro Lett. 3, 305-309 (2014).

[10] a) Grätz, A., Wolfrum, B. \& Borchardt, L. Mechanochemical Suzuki polycondensation - from linear to hyperbranched polyphenylenes. Green Chem. 19, 2973-2979 (2017).

b) Vogt, C. G. et al. Direct mechanocatalysis: Palladium as milling media and catalyst in the mechanochemical Suzuki polymerization. Angew. Chem. Int. Ed. 58, 18942-18947 (2019).

[11] Oh, C. Choi, E. H., Choi, E. J., Premkumar, T. \& Song, C. Facile solid-state mechanochemical synthesis of eco-friendly thermoplastic polyurethanes and copolymers using a biomass-derived furan diol. ACS Sustain. Chem. Eng. 8, 4400-4406 (2020).

[12] a) Ohn, N., Shin, J., Kim, S. S. \& Kim, J. G. ChemSusChem 10, 3529-3533 (2017).

b) Lee, G. S., Moon, B. R., Shin, J. \& Kim, J. G. Mechanochemical synthesis of poly(lactic acid) block copolymers: overcoming the miscibility of the macroinitiator, monomer and catalyst under solvent-free conditions. Polym. Chem. 10, 539-545 (2019).

c) Park, S. \& Kim, J. G. Mechanochemical synthesis of poly (trimethylene carbonate)s: an example of rate acceleration. Beilstein J. Org. Chem. 15, 963-970 (2019).

[13] Cho, H. Y. \& Bielawski, C. W. Atom Transfer Radical Polymerization in the Solid-State. Angew. 
Chem. Int. Ed. 59, 13929-13935 (2020).

[14] a) Ohn, N. \& Kim, J. G. Mechanochemical post-polymerization modification: solvent-free solidstate synthesis of functional polymers. ACS Macro. Lett. 7, 561-565 (2018).

b) Fiss, B. G., Hatherly, L., Stein, R. S., Friščić, T. \& Moores, A. Mechanochemical phosphorylation of polymers and synthesis of flame-retardant cellulose nanocrystals. ACS Sustain. Chem. Eng. 7, 7951-7959 (2019).

c) Malca, M. Y., Ferko, P.-O., Friščić, T. \& Moores, A. Solid-state mechanochemical $\omega$ functionalization of poly(ethylene glycol). Beilstein J. Org. Chem. 13, 1963-1968 (2017).

d) Ashlin, M. \& Hobbs, C. E. Post-polymerization thiol substitutions facilitated by mechanochemistry. Macromol. Chem. Phy. 220, 1900350 (2019).

[15] a) He, X. et al. Mechanochemical kilogram-scale synthesis of noble metal single-atom catalysts. Cell. Rep. Phys. Sci. 1, 100004 (2020).

b) Seo, T., Toyoshima, N, Kubota, K. \& Ito, H. Tackling solubility issues in organic synthesis: solid-state cross-coupling of insoluble aryl halides. J. Am. Chem. Soc. 143, 6165-6175 (2021).

[16] a) Bielawski, C. W. \& Grubbs, R. H. Living ring-opening metathesis polymerization. Prog. Polym. Sci. 32, 1-29 (2007).

b) Sutthasupa, S., Shiotsuki, M. \& Sanda, F. Recent advances in ring-opening metathesis polymerization, and application to synthesis of functional materials. Polym. J. 42, 905-915 (2010). c) Ogba, O. M., Warner, N. C., O'Leary, D. J. \& Grubbs, R. H. Recent advances in rutheniumbased olefin metathesis. Chem. Soc. Rev. 47, 4510-4544 (2018).

d) Clavier, H., Grela, K., Kirschning, A., Mauduit, M. \& Nolan, S. P. Sustainable concepts in olefin metathesis. Angew. Chem. Int. Ed. 46, 6786-6801 (2007).

[17] a) Grau, E. \& Mecking, S. Polyterpenes by ring opening metathesis polymerization of caryophyllene and humulene. Green Chem. 15, 1112-1115 (2013). 
b) Bai, Y. et al. Ring opening metathesis polymerisation of a new bio-derived monomer from itaconic anhydride and furfuryl alcohol. Green Chem. 18, 3945-3948 (2016).

c) Dell'Acqua, A., Stadler, B. M., Kirchhecker, S., Tin, S. \& De Vries, J. G. Scalable synthesis and polymerisation of a $\beta$-angelica lactone derived monomer. Green Chem. 16, 5267-5273 (2020).

[18] Dubé, M. A. \& Salehpour, S. Applying the principles of green chemistry to polymer production technology. Macromol. React. Eng. 8, 7-28 (2014).

[19] a) Granato, A. V., Santos, A. G. \& dos Santos, E. N. p-Cymene as solvent for olefin metathesis: matching efficiency and sustainability. ChemSusChem 10, 1832-1837 (2017).

b) Skowerski, K., Biatecki, J., Tracz, A. \& Olszewski, T. K. An attempt to provide an environmentally friendly solvent selection guide for olefin metathesis. Green Chem. 16, 1125-1130 (2014).

b) Thomas, P. A. \& Marvey, B. B. Room temperature ionic liquids as green solvent alternatives in the metathesis of oleochemical feedstocks. Molecules 21, 184 (2016).

c) Rajkiewicz, A. A., Skowerski, K., Trzaskowski, B., Kajetanowicz, A. \& Grela, K. 2Methyltetrahydrofuran as a solvent of choice for spontaneous metathesis/isomerization sequence. ACS Omega 4, 1831-1837 (2019).

d) Fürstner, A. et al. Olefin metathesis in supercritical carbon dioxide. J. Am. Chem. Soc. 123, 9000-9006 (2001).

e) Shin, H. G., Lee, H. S., Hong, E. J. \& Kim, J. G. Study of green solvents for ruthenium alkylidene mediated ring-opening Metathesis Polymerization. Bull. Korean Chem. Soc. 42, 502-505 (2021).

[20] Larabi, C. et al. Solvent-free ring-opening metathesis polymerization of norbornene over silicasupported tungsten-oxo perhydrocarbyl catalysts. Macromol. Rapid. Commun. 37, 1832-1836 (2016).

[21] Shetty, M., Kothapalli, V. A. \& Hobbs, C. E. Toward the (nearly) complete elimination of solvent 
waste in ring opening metathesis polymerization (ROMP) reactions. Polymer 80, 64-66 (2015).

[22] a) Rybak, A. \& Meier, M. A. R. Acyclic diene metathesis with a monomer from renewable resources: Control of molecular weight and one-step preparation of block copolymers. ChemSusChem 1, 542-547 (2008).

b) Fokou, P. A. \& Meier, M. A. R. Acyclic triene metathesis polymerization with chain-stoppers: molecular weight control in the synthesis of branched polymers. Macromol. Rapid Commun. 29, $1620-1625$ (2008).

[23] Do, J.-L., Mottillo, C., Tan, D., Štrukil, V. \& Friščić, T. Mechanochemical ruthenium-catalyzed olefin metathesis. J. Am. Chem. Soc. 137, 2476-2479 (2015).

[24] a) Choi, T.-L. \& Grubbs, R. H. Controlled living ring-opening-metathesis polymerization by a fastinitiating ruthenium catalyst. Angew. Chem. Int. Ed. 42, 1743-1746 (2003).

b) Vidavsky, Y., Anaby, A. \& Lemcoff, N. G. Chelating alkylidene ligands as pacifiers for ruthenium catalysed olefin metathesis. Dalton Trans. 41, 32-43 (2012).

c) Engle, K. M. et al. Origins of initiation rate differences in ruthenium olefin metathesis catalysts containing chelating benzylidenes. J. Am. Chem. Soc. 137, 5782-5792.

d) Scholl, M., Ding, S., Lee, C. W. \& Grubbs, R. H. Synthesis and activity of a new generation of ruthenium-based olefin metathesis catalysts coordinated with 1, 3-dimesityl-4, 5-dihydroimidazol2-ylidene ligands. Org. Lett. 1, 953-956 (1999).

e) Huang, J., Steven, E. D., Nolan, S. P. \& Peterson, J. L. Olefin metathesis-active ruthenium complexes bearing a nucleophilic carbene ligand. J. Am. Chem. Soc. 121, 2674-2678 (1999).

[25] Ritter, T., Hejl, A., Wenzel, A. G., Funk, T. W. \& Grubbs, R. H. A standard system of characterization for olefin metathesis catalysts. Organometallics 25, 5740-5745 (2006).

[26] Sutthasupa, S., Shiotsuki, M. \& Sanda, F. Recent advances in ring-opening metathesis 
polymerization, and application to synthesis of functional materials. Polym. J. 42, 905-915 (2010).

[27] a) Chen, L., Regan, M. \& Mack, J. The choice is yours: using liquid-assisted grinding to choose between products in the palladium-catalyzed dimerization of terminal alkynes. ACS Catalysis $\mathbf{6}$, 868-872 (2016).

b) Howard, J. L., Sagatov, Y., Repusseau, L., Schotten, C. \& Browne, D. L. Controlling reactivity through liquid assisted grinding: the curious case of mechanochemical fluorination. Green Chem. 19, 2798-2802 (2017).

[28] a) Isarov, S. A. \& Pokorski, J. K. Protein ROMP: Aqueous graft-from ring-opening metathesis polymerization. ACS Macro Lett. 4, 969-973 (2015).

b) Foster, J. C., Varlas, S., Blackman, L. D., Arkinstall, L. A. \& O’Reilly, R. K. Ring-opening metathesis polymerization in aqueous media using a macroinitiator approach. Angew. Chem. Int. Ed. 57, 10672-10676 (2018).

c) Chruch, D. C., Takiguchi, L. \& Pokorski, J. K. L] Optimization of ring-opening metathesis polymerization (ROMP) under physiologically relevant conditions. Polym. Chem. 11, 4492-4499 (2020).

[29] a) Xia, Y., Kornfield, J. A. \& Grubbs, R. H. Efficient synthesis of narrowly dispersed brush polymers via living ring-opening metathesis polymerization of macromonomers. Macromolecules 42, 3761-3766 (2009).

b) Xia, Y., Olsen, B. D., Kornfield, J. A. \& Grubbs, R. H. Efficient synthesis of narrowly dispersed brush copolymers and study of their assemblies: The importance of side chain arrangement. $J$. Am. Chem. Soc. 131, 18525-18532 (2009).

[30] a) Raffa, P., Wever, D. A. Z., Picchioni, F. \& Broekhuis, A. A. Polymeric surfactants: synthesis, properties, and links to applications. Chem. Rev. 115, 8504-8563 (2015). 
b) Banerjee, P., Jana, S. \& Mandal, T. K. Coulomb interaction-driven UCST in poly(ionic liquid) random copolymers. Eur. Polym. J. 133, 109747 (2020).

c) Ramos-Garcés, M. V. et al. Understanding the ionic activity and conductivity value differences between random copolymer electrolytes and block copolymer electrolytes of the same chemistry. RSC Adv. 11, 15078-15084 (2021).

[31] a) Okamura, H., Takarori, Y., Tsunooka, M. \& Shirai, M. Synthesis of random and block copolymers of styrene and styrenesulfonic acid with low polydispersity using nitroxide-mediated living radical polymerization technique. Polymer 43, 3155-3162 (2002).

b) Hu, H., Yuan, W., Jia, Z. \& Baker, G. L. Ionic liquid-based random copolymers: a new type of polymer electrolyte with low glass transition temperature. RSC Adv. 5, 3135-3140 (2015).

[32] Lee, J. W., Park, J., Lee, J., Park, S., Kim, J. G. \& Kim, B.-S. Solvent-free mechanochemical postpolymerization modification of ionic polymers. ChemSusChem 14, 3801-3805 (2021). 